\title{
Results of Research about Forming Professional Subjectivity of Future Physical Education Teachers
}

\author{
Bytsiuk Viktoriia* \\ Classical Private University, 70-b, Zhukovskiystr., Zaporizhzhya, 69002 Ukraine \\ *Corresponding Author: Bytsiuk Viktoriia, Classical Private University, 70-b, Zhukovskiystr, \\ Zaporizhzhya, 69002 Ukraine

\begin{abstract}
The author represents the conceptual idea of forming professional subjectivity of future physical education teachers during their vocational training. The article provides plan of activities of the research aiming to check efficiency of author's conceptual idea. The researcher shows and deems results of the investigation in the experimental and test (reference) higher education establishments. There is a comprehensive conclusion about efficiency of conceptual points embedding in the sphere of forming professional subjectivity of future physical education teachers. Some promising directions of the future research are defined.
\end{abstract}

Keywords: professional subjectivity, conceptual idea, forming, research, future physical education teachers

\section{INTRODUCTION}

Professional activity of physical education teachers is one of the factors of providing well-balanced physical development of children and youth, their aptitude for healthy fully-fledged life. Efficiency of this activity is determined by level of teacher's subjectivity and represents a person as a policy maker of working activity, who is capable to set and make adjustments to one's goal, be aware of motives, ready for own planning and evaluating own professional actions.

There is a great range of scientific researches that reveal main points and features of person's subjectivity, such as S. Rubinstein [2], Z. Ryaby` kina [3], G. Fomenko [3], M. Shchukina [4; 5]. Nevertheless, the analysis of the scientific works shows that nowadays there is a lack of information about theoretical and methodological principles of professional subjectivity forming of future physical education teachers in reference to fundamental professional education process, and this, in its turn, can interfere quality training and performance of the experts.

We strongly believe that all the evidence represented above allows identifying forming of professional subjectivity of future physical education teachers as a scientific issue, and its solving is connected to improvement of syllabus, curriculum and academic programs, regulatory documentation, and methodical guidance of educational process of higher education establishment.

In order to find out the solution for the issue the author conducted the research and its results are described in the article.

\subsection{Purpose and Objectives}

The purpose of the article is to reveal the results of the scientific research about forming of professional subjectivity of future physical education teachers during vocational training process.

\subsection{Methods}

Methods of the research: analysis of the scientific resources to represent the main points of the theoretical background; measuring and evaluation of the efficient feature using psychological methodology and external appraisement; pedagogical experiment; statistical techniques.

\section{RESUltS}

Firstly, we enunciated the main idea, construct of forming professional subjectivity of future physical education teachers. It can be described in several points. 
The first point represents the idea that professional subjectivity of future physical education teachers is a professional characteristic of being able to become a subject of pedagogical activity, set and modulate the aim of the activity according to social requirements, more than that, plan and evaluate one's own actions to implement pedagogical position in the framework of educational process.

The second point is about peculiarities of the theoretical background of forming professional subjectivity of future physical education teachers. As a rule, they are imperative statements of Bologna process, competency based, activity, reflexive, context approach, humanistic pedagogics and psychology, text theory, methodology of empirical investigation in sociology, pedagogics and psychology.

The third point is about pedagogics conditions of forming professional subjectivity, and they are:

$>$ improvement of the provided subjects content with thematic modules focused on forming professional subjectivity;

$>$ creating positive image of professional prospects;

$>$ forming reflective environment to make students aware of the contradiction between preferable and current status of professional competencies development;

$>$ encouraging students to perform their personality in the spare time and extracurricular socially significant activities;

$>$ Implementation of check-out methodology focused on evaluation of the mentioned professional feature of future physical education teachers.

> The fourth point reveals that professional subjectivity can be described by virtue of ontological, personality, activity and social-pedagogical criteria. There are special features of professional subjectivity such as:

> In frameworks of ontological criterion: assertiveness, self-sufficiency, integrity, frankness, creativity, dignity;

$>$ In frameworks of personality criterion: maturity of professional self-image, professional identification; professional success and personal development need; fidelity to principle of world outlook guidelines;

- In frameworks of activity criterion: systematic, constructive and consistent performance of own pedagogical attitude in case of pedagogical issues solving; deliberateness in pedagogical performance; justice in pedagogical conflicts regulation;

- In frameworks of social-pedagogical criterion: leader's position among students and colleagues.

The essential part of the investigation is an empiric study, which is based on special scheme for equivalent groups aiming to compare efficient features of independent samples of experimental and reference higher education establishments at the beginning and the end of the experiment [1].

Classical Private University, city Zaporizhzhia (Ukraine) was the experimental higher education establishment. As a reference (test) higher education establishment we chose Zaporizhzhia National University (Ukraine). Experimental research took 4 years (from 2015 till 2019). Amount of students in each of the equivalent group was 21 participants ( 9 female and 12 male ones).

Evaluation of efficient features in experimental and reference higher education establishments was done due to methodology by M. Shchukina (ontology criterion evaluation); author's survey (personality criterion evaluation); methodology "Pedagogical situations" by R. Niemov (activity criterion evaluation); external evaluation of performance by students and colleagues (socialpedagogical criterion evaluation).

We did evaluating actions during the last semester of bachelor degree gaining before the state qualification examination.

We did data processing by means of software package Statistica 10.

The table gives data about levels of professional subjectivity as well as the data interpretation.

Table1: Results of multi-way tables' data about level of subjectivity of future physical education teachers

\begin{tabular}{|c|c|c|c|c|c|}
\hline \multirow[t]{2}{*}{ Sample } & \multirow[t]{2}{*}{ Year } & \multirow[t]{2}{*}{ Statistic index } & \multicolumn{3}{|c|}{ Level } \\
\hline & & & Low & Intermediate & High \\
\hline \multicolumn{6}{|c|}{ Ontological criterion (methodology "Level of personality subjectivity development" by M. Shchukina) } \\
\hline \multirow{2}{*}{$\begin{array}{l}\text { Ref. } \\
\text { HEE }\end{array}$} & \multirow[t]{2}{*}{2015} & Frequency & 6 & 13 & 2 \\
\hline & & $\%$ & $28.57 \%$ & $61.90 \%$ & $9.52 \%$ \\
\hline
\end{tabular}


Results of Research about Forming Professional Subjectivity of Future Physical Education Teachers

\begin{tabular}{|c|c|c|c|c|c|}
\hline & 2019 & Frequency & 5 & 14 & 2 \\
\hline & & $\%$ & $23.81 \%$ & $66.67 \%$ & $9.52 \%$ \\
\hline \multirow[t]{4}{*}{ Exper. HEE } & \multirow[t]{2}{*}{2015} & Frequency & 7 & 11 & 3 \\
\hline & & $\%$ & $33.33 \%$ & $52.38 \%$ & $14.29 \%$ \\
\hline & \multirow[t]{2}{*}{2019} & Frequency & 2 & 11 & 8 \\
\hline & & $\%$ & $9.52 \%$ & $52.38 \%$ & $38.10 \%$ \\
\hline \multicolumn{6}{|c|}{ Personalality criterion (Author's survey) } \\
\hline \multirow{4}{*}{$\begin{array}{l}\text { Ref. } \\
\text { HEE }\end{array}$} & \multirow[t]{2}{*}{2015} & Frequency & 8 & 10 & 3 \\
\hline & & $\%$ & 38.10 & 47.62 & 14.29 \\
\hline & \multirow[t]{2}{*}{2019} & Frequency & 10 & 10 & 1 \\
\hline & & $\%$ & 47.62 & 47.62 & 4.76 \\
\hline \multirow[t]{4}{*}{ Exper. HEE } & \multirow[t]{2}{*}{2015} & Frequency & 8 & 11 & 2 \\
\hline & & $\%$ & $38.10 \%$ & $52.38 \%$ & $9.52 \%$ \\
\hline & \multirow[t]{2}{*}{2019} & Frequency & 0 & 9 & 12 \\
\hline & & $\%$ & 0 & 42.86 & 57.14 \\
\hline & \multirow{3}{*}{$\begin{array}{l}\text { Activit } \\
2015\end{array}$} & terion (Meth & agogical s & ons" by R & \\
\hline Ref. & & Frequency & 8 & 11 & 2 \\
\hline \multirow{3}{*}{ HEE } & & $\%$ & $38.10 \%$ & $52.38 \%$ & $9.52 \%$ \\
\hline & \multirow[t]{2}{*}{2019} & Frequency & 9 & 9 & 3 \\
\hline & & $\%$ & $42.86 \%$ & $42.86 \%$ & $14.29 \%$ \\
\hline \multirow[t]{4}{*}{ Exper. HEE } & \multirow[t]{2}{*}{2015} & Frequency & 8 & 10 & 3 \\
\hline & & $\%$ & $38.10 \%$ & $47.62 \%$ & $14.29 \%$ \\
\hline & \multirow[t]{2}{*}{2019} & Frequency & 1 & 12 & 8 \\
\hline & & $\%$ & $4.76 \%$ & $57.14 \%$ & $38.10 \%$ \\
\hline \multicolumn{6}{|c|}{ Social-pedagogical criterion (evaluation by students and colleagues) } \\
\hline \multirow{4}{*}{$\begin{array}{l}\text { Ref. } \\
\text { HEE }\end{array}$} & \multirow[t]{2}{*}{2015} & Frequency & 4 & 15 & 2 \\
\hline & & $\%$ & $19.05 \%$ & $71.43 \%$ & $9.52 \%$ \\
\hline & \multirow[t]{2}{*}{2019} & Frequency & 6 & 12 & 3 \\
\hline & & $\%$ & $28.57 \%$ & $57.14 \%$ & $14.29 \%$ \\
\hline \multirow[t]{4}{*}{ Exper. HEE } & \multirow[t]{2}{*}{2015} & Frequency & 8 & 12 & 1 \\
\hline & & $\%$ & $38.10 \%$ & $57.14 \%$ & $4.76 \%$ \\
\hline & \multirow[t]{2}{*}{2019} & Frequency & 2 & 9 & 10 \\
\hline & & $\%$ & $9.52 \%$ & $42.86 \%$ & $47.62 \%$ \\
\hline
\end{tabular}

As the table 1 shows multi-way tables' data about level of subjectivity of future physical education teachers within certain time periods, and according to particularly defined criteria in experimental and reference higher education establishments, it gives the evidence to claim the next statements.

\subsection{Ontological Criterion}

Evaluation of level of subjectivity of future physical education teachers in frameworks of ontological criterion, which characterizes moral courage of the person, one's determination to achieve "transpersonal" goals of one's life, in their turn, the goals become obvious by means of self-definition and self-fulfillment as main indexes of mental being. The scientific measuring shows that subjectivity of future physical education teachers in the sample of reference higher education establishment has not experienced any remarkable changes. In particular, in this education establishment there were $28.57 \%$ of future physical education teachers with low level of subjectivity at the beginning of the experiment, however, at the test stage the figure increased $-23.81 \%$; there were $67.9 \%$ of participants with intermediate subjectivity level, and at the test stage the index became $66.67 \%$; at the beginning of the experiment there were $9.52 \%$ of students with high subjectivity level, and this figure was the same at the test stage. In experimental higher education establishment fluctuation of the quantity of students with low, intermediate and high levels of subjectivity was more significant. At the beginning of the experiment there were $33.33 \%$ of students with low subjectivity level, and at the test stage the figure changed to $9.52 \%$; amount of students with intermediate subjectivity level was $52.38 \%$, and this index was constant at all stages of the experiment; among high subjectivity level students the figures were $14.29 \%$ and the final result was $38.1 \%$.

According to the results of the research, evaluation in frameworks of ontological criterion shows the general tendency of reduction of quantity of future teachers with low subjectivity level in experimental higher education establishment and absence of this tendency in reference higher education establishment. 


\subsection{Personality Criterion}

Evaluation of future physical education teachers, as a representatives of experimental and reference establishments, in the frameworks of personality criterion, that is based on personality features of physical education teacher, and are linked to person's professional fulfillment, proved that in the scientific investigation subjectivity of future physical education teachers (the sample of reference higher education establishment) almost has not changed. For example, in this educational establishment at the beginning of the experiment, in 2015 , there were $38.1 \%$ of students with low level of subjectivity, but at the test stage the figure increased a little to $47.62 \%$; the amount of future teachers with intermediate subjectivity level was constant $-47.62 \%$; with high level of subjectivity there were $14.29 \%$, but at the test stage the figure reduced to $4.76 \%$. In the experimental higher education establishment changes of quantity of students with low, intermediate and high levels of subjectivity were more significant. At the beginning of the experiment there were $38.1 \%$ of students with low subjectivity level, but at the test stage there were no such participants $(0 \%)$; the amount of students with intermediate subjectivity level was $52.38 \%$, but it changed to $42.86 \%$; there were $9.52 \%$ of students with high subjectivity level, and this quantity decreased to $57.74 \%$.

Having analyzed the data, we come to the conclusion that evaluation in the frameworks of personality criterion depicts a common tendency - reduction of quantity of future teachers with low and intermediate levels of subjectivity in experimental higher education establishment and absence of this tendency in reference establishment.

\subsection{Activity Criterion}

Evaluation of future physical education teachers in the frameworks of activity criterion, that characterizes maturity of self-fulfillment patterns, and, in their turn, these patterns help physical education teacher change social and professional activity according to own ideas, represented that subjectivity of future physical education teachers in the sample of reference higher education establishment did not get significant changes. In particular, at the beginning of the experiment (2015) in this establishment there were $38.1 \%$ of future physical education teachers with low level of subjectivity, but at the test stage $-42.86 \%$; the amount of participants with intermediate subjectivity level was $52.38 \%$, changed into $42.86 \%$; with high subjectivity level $-9.52 \%$ at the beginning of the experiment, at the end $-14.29 \%$. In experimental higher education establishment quantity fluctuation of students with low, intermediate and high subjectivity levels was significant. At the beginning of the experiment $-38.1 \%$ of the students with low subjectivity level, at the test stage the amount was $-4.76 \% ; 47.62 \%$ of students with intermediate subjectivity level, at the test stage the figure increased $-57.14 \%$; students with high subjectivity level at the beginning of the experiment $14.29 \%$, at the test stage $-38.1 \%$ students.

The analysis of the represented data shows, that evaluation in frameworks of activity criterion proves the general tendency of reducing the amount of future teachers with low and intermediate subjectivity levels, as well as corresponding increasing quantity of students with high level of this professional feature in experimental higher education establishment and absence of this tendency in reference higher education establishment.

\subsection{Social-Pedagogical Criterion}

Evaluation of subjectivity level of future physical education teachers in frameworks of socialpedagogical criterion, which indicates teacher's authority, recognition of outstanding achievements, knowledge, skills, habits, competences, that cause respect and make students and colleagues take into account teacher's thoughts, revealed that in the experimental research respondents' subjectivity in reference higher education establishment sample did not have a great fluctuation. In particular, there were $19.05 \%$ of future physical education teachers with low subjectivity level at the beginning of experiment and $28.57 \%$ at the end, amount of future teachers with intermediate subjectivity level changed from $71.43 \%$ to $57.14 \%$; and from $9.52 \%$ to $14,29 \%$ students with high subjectivity level in this university. There were significant changes of amount of low, intermediate, high subjectivity level categories in experimental university. At the beginning of the experiment amount of students with low subjectivity level changed from $38.1 \%$ to $9.52 \%$; with intermediate subjectivity level changed from $57.14 \%$ to $42.86 \%$; with high subjectivity level changed from $4.67 \%$ to $47.62 \%$.

The analyzed data show, that evaluation in frameworks of social-pedagogical criterion represents general tendency of reducing the amount of future teachers with low subjectivity level in the 
experimental higher education establishment and absence of that in the reference establishment, as it is seen.

The obtained results preliminarily point that purposeful creation of designed pedagogical conditions of professional subjectivity forming of future physical education teachers in the experimental higher education establishment makes significant growing an amount of future teachers with high and intermediate levels by each criterions. The amount of students with high and intermediate subjectivity level did not change a lot in the reference university.

Statistical verification difference of results of forming subjectivity of future physical education teachers in the experimental and the reference universities is made according to Mann-Whitney criterion.

The results of comparing progress level of this professional feature by this criterion at the beginning and at the end of experiment are given in table 2.

Table2: The results of comparing progress level of students' subjectivity in experimental and reference establishments by Mann-Whitney criterion at the beginning and at the end of experiment

\begin{tabular}{|l|l|l|l|l|l|}
\hline \multirow{2}{*}{ Criterion } & \multicolumn{2}{c|}{ Rank sum } & U & p-level & Statistical hypothesis \\
\cline { 2 - 6 } & $\begin{array}{c}\text { Exper. HEE } \\
(\mathbf{n = 2 1 )}\end{array}$ & Ref.HEE(n=21) & & \\
\hline 2015 & 449,5 & 453,5 & 218,5 & 0,970 & $\mathrm{H}_{0}$ \\
\hline Ontological & 445,0 & 458,0 & 214,0 & 0,880 & $\mathrm{H}_{0}$ \\
\hline Personality & 458,0 & 445,0 & 214,0 & 0,880 & $\mathrm{H}_{0}$ \\
\hline Activity & 498,0 & 174,0 & 0,247 & $\mathrm{H}_{0}$ \\
\hline Social-Pedagogical & 405,0 & 144,0 & 0,056 & $\mathrm{H}_{0}$ \\
\hline 2019 & 528,0 & 60,0 & 0,001 & $\mathrm{H}_{1}$ \\
\hline Ontological & 612,0 & 291,0 & 118,5 & 0,011 & $\mathrm{H}_{1}$ \\
\hline Personality & 553,5 & 349,5 & 132,0 & 0,027 & $\mathrm{H}_{1}$ \\
\hline Activity & 363,0 &
\end{tabular}

As it seen in the table 2, there was no statistical difference in the amount of future physical education teachers with low, intermediate, high subjectivity level between the experimental and the reference higher education establishment samples at the beginning of experiment in 2015. The result is predictable because observable students' samples had no big difference in gender, age, etc.

At the end of the experiment the difference in the frameworks of all subjectivity criteria except ontological one between the experimental and the reference higher education establishment was marked at $p<0,05$. Comparison by ontological criterion indicated remarkable difference $(p=0,056)$, but it is not valid at that significant level.

The conclusion on the given data confirms that students' professional training in professional subjectivity forming context was more effective in the experimental higher education establishment than in the reference higher education establishment.

Dynamics of students' subjectivity development in the experimental higher education establishment and the reference one is additionally rated for more valid conclusions. The dynamics presence is confirmed statistically by comparing empirical data according to Mann-Whitney criterion $(p<0,05)$ in the experimental higher education establishment and absence in the reference higher education establishment. The result of comparison is given in the table 3.

Table3: Results comparing the subjectivity levels of students in experimental and reference higher education establishments at the beginning and the ending of the experiment

\begin{tabular}{|c|c|c|c|c|c|}
\hline \multirow[t]{2}{*}{ Criteria } & \multicolumn{2}{|c|}{ Rank sum } & \multirow[t]{2}{*}{$\mathbf{U}$} & \multirow{2}{*}{$\begin{array}{c}\text { p- } \\
\text { piв. }\end{array}$} & \multirow{2}{*}{ Stat. Hyp. } \\
\hline & $2015 p$ & $2019 p$ & & & \\
\hline Ref. HEE $(n=20)$ & & & & & \\
\hline Ontological & 442,0 & 461,0 & 211,0 & 0,821 & $\mathrm{H}_{0}$ \\
\hline Personality & 482,5 & 420,5 & 189,5 & 0,443 & $\mathrm{H}_{0}$ \\
\hline Activity & 454,5 & 448,5 & 217,5 & 0,950 & $\mathrm{H}_{0}$ \\
\hline Social-Pedagogical & 462,0 & 441,0 & 210,0 & 0,801 & $\mathrm{H}_{0}$ \\
\hline
\end{tabular}




\begin{tabular}{|l|l|l|l|l|l|}
\hline Ontological & 371,5 & 531,5 & 140,5 & 0,046 & $\mathrm{H}_{1}$ \\
\hline Personality & 310,5 & 592,5 & 79,5 & 0,001 & $\mathrm{H}_{1}$ \\
\hline Activity & 356,0 & 547,0 & 125,0 & 0,017 & $\mathrm{H}_{1}$ \\
\hline Social-Pedagogical & 333,0 & 570,0 & 102,0 & 0,003 & $\mathrm{H}_{1}$ \\
\hline
\end{tabular}

As it seen from the table 2 , the dynamics of subjectivity forming of future physical education teachers in the reference higher education establishment has no confirmation by any of the criterion. At the same time in the experimental higher education establishment this dynamics is observed by all the criteria and can be considered as statistically valid at the relevance level $\mathrm{p}<0,05$.

\section{CONCLUSION}

Now therefore, task execution of the scientific research proved expediency and efficiency of the author's statements about forming subjectivity of future physical education teachers during professional training. In particular, the data received due to pedagogical experiment acknowledged that:

- At the beginning of the experiment subjectivity development of students by any of the criteria in reference and experimental higher education establishments did not have statistically-valid difference according to Mann-Whitney criterion $(\mathrm{p}<0,05)$;

- At the end of the experiment comparison of subjectivity development levels in reference and experimental higher education establishments represented significant difference between the samples;

- Comparing subjectivity levels of future physical education teachers at the beginning and at the end of the experiment showed valid dynamics of this professional feature maturing in experimental higher education establishment, but absence of this valid dynamics according to all criteria in reference higher education establishment.

The findings of the research prove, that in experimental higher education establishment contrary to reference higher education establishment the subjectivity development of future physical education teachers have occurred more efficiently, confirming in this way efficiency of designed by author conceptual statements about forming this professional feature.

\section{REFERENCES}

[1] Cambell D. T., Stanley J. C. (1963) Experimental and quasi-experimental designs for research. Boston: Houghton Mifflin Company. 84.

[2] Rubynshtein S. L. (2003) Bytye y soznanye [Being and consciousness] Chelovek y myrSPb, 590 [in Russian].

[3] Ryabikina Z. I. Fomenko G. Yu. (2009) Subyektno-bytiynyypodkhod: preyemstvennosttraditsiy [Subjective-existential approach: continuity of traditions. Person. Community. Control]. Chelovek. Soobshchestvo. Upravleniye.4. 26-37. Retrieved from: http://chsu.kubsu.ru/arhiv/2009_4/2009_4_ RyabikinaFomenko.pdf [inRusian].

[4] Shchukina M.A. (2004) Osobennostirazvitiyasubyektnostilichnosti v podrostkovomvozraste [Features of the development of personality subjectivity in adolescence]. Dissertation for the degree of a candidate of psychology sciences (PhD). Tymen.168 [in Rusian].

[5] Shchukina M. A. (2015). Psikhologiyasamorazvitiyalichnosti : subyektnyy podkhod [Psychology of personality self-development: a subjective approach]. Dissertation for the degree of a candidate of psychology sciences (PhD). St.Petersburg. 360 [inRusian].

Citation: Bytsiuk Viktoriia. "Results of Research about Forming Professional Subjectivity of Future Physical Education Teachers". International Journal of Humanities Social Sciences and Education (IJHSSE), vol. 6, no.10, 2019, pp. 104-109. doi: http://dx.doi.org/10.20431/2349-0381.0610012.

Copyright: (0) 2019 Authors. This is an open-access article distributed under the terms of the Creative Commons Attribution License, which permits unrestricted use, distribution, and reproduction in any medium, provided the original author and source are credited. 